Article

\title{
Higher Serum 25-Hydroxyvitamin D Concentrations Associate with a Faster Recovery of Skeletal Muscle Strength after Muscular Injury
}

\author{
Tyler Barker $^{1, *}$, Vanessa T. Henriksen ${ }^{1}$, Thomas B. Martins ${ }^{2}$, Harry R. Hill ${ }^{2,3}$,
}

Carl R. Kjeldsberg ${ }^{2,3}$, Erik D. Schneider ${ }^{4}$, Brian M. Dixon ${ }^{4}$ and Lindell K. Weaver ${ }^{5,6,7}$

1 The Orthopedic Specialty Hospital, Murray, UT 84107, USA;

E-Mail: vanessa.henriksen@imail.org

2 ARUP Laboratories, Institute for Clinical and Experimental Pathology, Salt Lake City,

UT 84108, USA; E-Mails: martintb@aruplab.com (T.B.M.); harry.hill@path.utah.edu (H.R.H.);

ckbike@comcast.net (C.R.K.)

3 Department of Pathology, Pediatrics and Medicine, University of Utah, Salt Lake City, UT 84132, USA

4 USANA Health Sciences, Inc., Salt Lake City, UT 84120, USA;

E-Mails: erik.schneider@us.usana.com (E.D.S.); brian.dixon@us.usana.com (B.M.D.)

5 Hyperbaric Medicine, Intermountain Medical Center, Murray, UT 84107, USA;

E-Mail: lindell.weaver@imail.org

6 LDS Hospital, Salt Lake City, UT 84143, USA

7 School of Medicine, University of Utah, Salt Lake City, UT 84132, USA

* Author to whom correspondence should be addressed; E-Mail: tyler.barker@imail.org; Tel.: +1-801-314-4951; Fax: +1-801-314-4862.

Received: 30 January 2013; in revised form: 18 March 2013 / Accepted: 29 March 2013 / Published: 17 April 2013

Abstract: The primary purpose of this study was to identify if serum 25-hydroxyvitamin D $(25(\mathrm{OH}) \mathrm{D})$ concentrations predict muscular weakness after intense exercise. We hypothesized that pre-exercise serum $25(\mathrm{OH}) \mathrm{D}$ concentrations inversely predict exercise-induced muscular weakness. Fourteen recreationally active adults participated in this study. Each subject had one leg randomly assigned as a control. The other leg performed an intense exercise protocol. Single-leg peak isometric force and blood $25(\mathrm{OH}) \mathrm{D}$, aspartate and alanine aminotransferases, albumin, interferon (IFN)- $\gamma$, and interleukin-4 were measured prior to and following intense exercise. Following exercise, serum 25(OH)D concentrations increased $(p<0.05)$ immediately, but within minutes, 
subsequently decreased $(p<0.05)$. Circulating albumin increases predicted $(p<0.005)$ serum 25(OH)D increases, while IFN- $\gamma$ increases predicted $(p<0.001)$ serum $25(\mathrm{OH}) \mathrm{D}$ decreases. Muscular weakness persisted within the exercise leg $(p<0.05)$ and compared to the control leg $(p<0.05)$ after the exercise protocol. Serum 25(OH)D concentrations inversely predicted $(p<0.05)$ muscular weakness (i.e., control leg $v$ s. exercise leg peak isometric force) immediately and days (i.e., 48-h and 72-h) after exercise, suggesting the attenuation of exercise-induced muscular weakness with increasing serum $25(\mathrm{OH}) \mathrm{D}$ prior to exercise. Based on these data, we conclude that pre-exercise serum $25(\mathrm{OH}) \mathrm{D}$ concentrations could influence the recovery of skeletal muscle strength after an acute bout of intense exercise.

Keywords: vitamin D; exercise; muscle strength; cytokines; albumin

\section{Introduction}

Vitamin D is a pleiotropic micronutrient that influences health across a range of physiological and pathophysiological conditions in humans. In the body, 25-hydroxyvitamin D $(25(\mathrm{OH}) \mathrm{D})$ is the most abundant circulating metabolite and most reliable indicator of vitamin D intake and storage [1]. Maintaining an adequate circulating concentration of $25(\mathrm{OH}) \mathrm{D}$ is, therefore, important to the physiological events moderated by vitamin $\mathrm{D}$.

In addition to its well-known regulation of calcium and mineral homeostasis, vitamin D also regulates genomic and non-genomic events that govern skeletal muscle function, for review see, for review [2-6]. These functions include the regulation of calcium handling and transport, the expression of cytoskeletal proteins, phosphate metabolism, cell proliferation and differentiation, and the activation of mitogen activated protein kinase signaling pathways in skeletal muscle [7-22]. These functions are established in experimental animal and cell culture studies, but less clear is the regulatory influence of vitamin D on skeletal muscle function in humans.

In physiological and pathophysiological conditions, muscular strength associates with serum $25(\mathrm{OH}) \mathrm{D}$ concentrations [23-35]. This association is prominent at deficient $(<20 \mathrm{ng} / \mathrm{mL})$ and insufficient (20 to $32 \mathrm{ng} / \mathrm{mL}$ ) serum 25(OH)D concentrations [25,36,37]. Despite the efficacy of supplemental vitamin $\mathrm{D}$ to increase serum 25(OH)D concentrations, however, ambiguity persists regarding the influence of supplemental vitamin D on skeletal muscle strength [30,38-43]. Nevertheless, it is inferred that increasing serum $25(\mathrm{OH}) \mathrm{D}$ from deficient to insufficient or sufficient (>32 ng/mL) concentrations attenuates muscular weakness.

Immediate (i.e., minutes to hours) and persistent (i.e., days) muscular weakness can follow intense exercise or a muscle-damaging event [44,45]. Muscular weakness after intense exercise or a muscle-damaging event could cause a predisposition to additional trauma. For example, muscular weakness due to injury could contribute to the development of stress fractures in military recruits, which interestingly, could be prevented by increasing serum $25(\mathrm{OH}) \mathrm{D}$ concentrations [46,47]. Likewise, low serum $25(\mathrm{OH}) \mathrm{D}$ concentrations contribute to muscular weakness and the increase in falls and bone 
fractures in elderly [36,48-54]. Increasing or maintaining an adequate serum $25(\mathrm{OH}) \mathrm{D}$ concentration, therefore, could preserve muscular strength after injury and protect against further injury.

Following intense exercise, serum $25(\mathrm{OH}) \mathrm{D}$ concentrations were not associated with muscular strength [55]. In that previous study, however, the serum $25(\mathrm{OH}) \mathrm{D}$ concentration and muscular strength relationship was examined 2-days after eccentric contractions [55]. In experimental rats, vitamin D (activated 7-dehyrocholesterol at 332,000 IU/kg of body mass) promoted muscle regeneration and accelerated the recovery of skeletal muscle strength after crush injury [19], which could possibly relate to the ability of vitamin D to regulate satellite cells in the repair of skeletal muscle [21].

Eccentric (i.e., active-lengthening) contractions of skeletal muscle induce muscle injury and a systemic inflammatory response [56], which in theory, could contribute to serum $25(\mathrm{OH}) \mathrm{D}$ concentration decreases [57-59]. Although the causative mechanism responsible for the serum $25(\mathrm{OH}) \mathrm{D}$ decrease during inflammation awaits future elucidation in humans, persuasive results reveal the regulatory influence of inflammatory cytokines on vitamin D metabolism in immune cells.

Interferon (IFN) $-\gamma$ is an inflammatory cytokine that influences vitamin D metabolism in immune cells $[60,61]$. In isolated peripheral immune cells, IFN- $\gamma$ increases $1 \alpha$-hydroxylase activity and mediates the conversion of $25(\mathrm{OH}) \mathrm{D}$ to 1,25-dihydroxyvitamin $\mathrm{D}(1,25(\mathrm{OH}) \mathrm{D})$ [60-65]. In contrast to IFN- $\gamma$, interleukin (IL)-4 is a cytokine that initiates the catabolism of $25(\mathrm{OH}) \mathrm{D}$ to 24,25 -dihydroxyvitamin D [65]. Following intense exercise, IFN- $\gamma$ decreases or remains unchanged [66-68] while IL-4 remains unchanged or below detection limits in the circulation $[69,70]$. Thus, given its regulation of vitamin D metabolism in immune cells, IFN- $\gamma$ changes could be inversely related to serum $25(\mathrm{OH}) \mathrm{D}$ concentration alterations after exercise.

Data suggest that serum $25(\mathrm{OH}) \mathrm{D}$ concentrations and muscular strength are not associated after exercise [55]. However, in that earlier study [55], it is possible that the imposed exercise protocol induced a systemic inflammatory response [56]. This is an important consideration because inflammation could modulate serum $25(\mathrm{OH}) \mathrm{D}$ concentrations, and consequentially, confound the interpretation between vitamin $\mathrm{D}$ and muscle strength [71]. To address this conundrum, the primary aim of this study was to identify if pre-exercise serum $25(\mathrm{OH}) \mathrm{D}$ concentrations predict immediate and persistent (i.e., several days) muscular weakness after intense exercise. We hypothesized that pre-exercise serum $25(\mathrm{OH}) \mathrm{D}$ concentrations inversely predict immediate and persistent muscular weakness after intense exercise. As the secondary aim of this study, we sought to identify if circulating cytokines predict serum $25(\mathrm{OH}) \mathrm{D}$ concentrations after intense exercise. We hypothesized that IFN- $\gamma$ changes inversely predict serum $25(\mathrm{OH}) \mathrm{D}$ concentration alterations.

\section{Experimental Section}

The Institutional Review Board at Intermountain Healthcare (Murray, UT, USA) approved this study. Recreationally active (i.e., at least $30 \mathrm{~min}$ of continuous exercise 3 times per week for 1 year prior to enrollment) subjects were informed of the experimental protocol and procedures and provided both written and verbal consent prior to participation. Subjects were excluded if: they were taking any dietary supplements or anti-inflammatory medications, suffered a lower leg injury during the previous year that required the use of crutches, were taking digoxin and antiarrhythmic medication(s), diagnosed with diabetes mellitus, impaired liver or kidney function, pregnant, morbidly obese (body 
mass index $(\mathrm{BMI})>40 \mathrm{~kg} / \mathrm{m}^{2}$ ), using corticosteroid medication, planning on increasing or decreasing the amount of time spent in the sun or tanning bed, or traveling south of $37^{\circ} \mathrm{N}$ in latitude during study participation. Subjects were also excluded if they had a history of: metabolic bone disease, skeletal muscle pathology, cardiac or peripheral cardiovascular system abnormalities, clotting disorders, coronary artery disease, peripheral vascular disease, stroke, cancer, hypercalcemia or parathyroid dysfunction, iron deficiency within the past year or a potential concern of iron deficiency, high cholesterol or triglycerides, high blood pressure, or the presence of strength or power output asymmetry (i.e., $>5 \%$ difference in peak isometric between legs). Potential subjects were excluded from study participation if they reported or showed any medical condition, under physician treatment, or taking any prescribed medication. During study participation, subjects were asked to keep their diet consistent with their regular eating habits during the previous year.

Data was collected during the winter (December to March) in Salt Lake City, UT, USA $\left(40^{\circ} \mathrm{N}\right.$ latitude). Subjects were asked to refrain from physical activity, and using steroids, aspirin, ibuprofen, naproxen sodium, acetaminophen, or other anti-inflammatory agents 72-h prior to the blood draw and strength testing procedures to remove the potential confounding influences of activity and anti-inflammatory agents on blood and strength testing results.

\subsection{Exercise Protocol}

In an attempt to minimize the bias of leg dominance, subjects that displayed greater than a 5\% difference in peak isometric force between legs were excluded from study participation. Following study inclusion, each subject had one leg randomly assigned as the control (CON) leg. The other leg performed an intense-stretch shortening contraction (SSC) protocol (Figure 1). The rationale for performing this protocol unilaterally was to assess isometric force within and between legs across time, and to allow each subject to serve as their own control.

Figure 1. Examples of the single-leg strength testing and the intense-stretch shortening contraction (SSC) protocol on the horizontal Plyo-press. (A) The weight stack resistance was overloaded to prevent sled movement in order to achieve isometric testing. (A-C) Subjects performed repetitive single-leg jumps during the SSC protocol. Illustrated below is an example of a subject in the push-off position (A), at peak height of the jump (B), and the subsequent landing (C) during the SSC protocol. Subjects performed 10 sets of 10 jumps with a 20 -s rest between each set at $75 \%$ of body mass on one leg only (i.e., SSC leg). Note: This figure is adapted with permission from [68]. Copyright (C) Barker et al.; licensee BioMed Central Ltd.

A

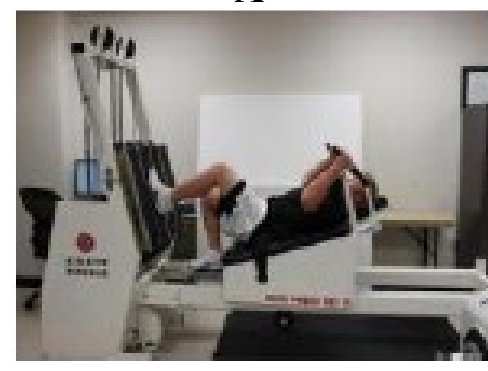

B

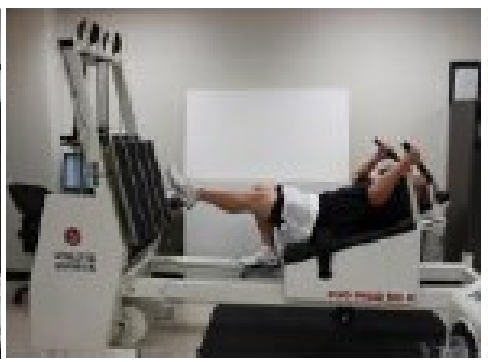

C

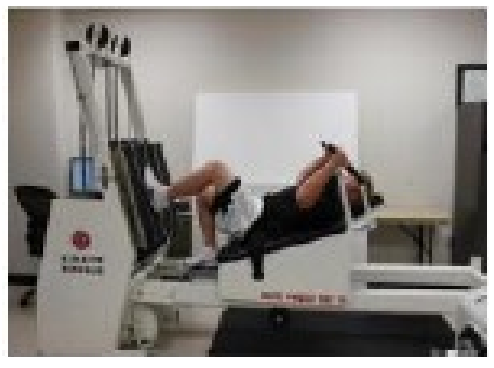


The purpose of the SSC protocol was to induce peak isometric force deficits that would persist for several days [68]. The SSC protocol consisted of 10 sets of 10 repetitive jumps at $75 \%$ of body mass with a $20 \mathrm{~s}$ rest between each set. Subjects were instructed and verbally encouraged to perform each set with maximal effort and to jump as high as possible through a full range of motion $\left(90^{\circ}\right.$ of knee flexion-to-full extension). Subjects performed presses through a full range of motion if they were unable to complete the jumps. If they were unable to complete presses, the exercise protocol was terminated. The mean number of jumps and presses completed during the SSC protocol were $62 \pm 9$ and $23 \pm 5$, respectively, while 7 ( 3 males and 4 females; age, $32 \pm 3$ years; height, $167 \pm 5 \mathrm{~cm}$; body mass, $76.8 \pm 8.7 \mathrm{~kg}$; body mass index, $27.1 \pm 1.7 \mathrm{~kg} / \mathrm{m}^{2}$ ) of the 14 subjects were unable to complete the SSC protocol due to fatigue or exhaustion. Of the subjects who completed the exercise protocol, 3 subjects (all males; age, $29 \pm 2$ years; height, $182 \pm 4 \mathrm{~cm}$; body mass, $85.3 \pm 5.4 \mathrm{~kg}$; body mass index, $25.7 \pm 1.6 \mathrm{~kg} / \mathrm{m}^{2}$ ) completed all the jumps and four subjects ( 3 males and 1 female; age, $33 \pm 2$ years; height, $176 \pm 7 \mathrm{~cm}$; body mass, $78.0 \pm 7.5 \mathrm{~kg}$; body mass index, $24.8 \pm 0.8 \mathrm{~kg} / \mathrm{m}^{2}$ ) completed the exercise protocol by performing a combination of jumps and presses. Circulating chemistries and leg strength were not significantly different between subjects who completed the exercise protocol compared to those who were unable to complete the exercise protocol (data not shown). Although 7 subjects were unable to complete the acute exercise protocol, all subjects $(n=14)$, completed the remainder of study protocol following the exercise protocol.

Subjects were allowed to consume water ad libitum during and following exercise protocol. The study protocol is illustrated in Figure 2.

Figure 2. Study protocol. Each subject provided eight fasting blood draws. The first blood draw was performed at baseline (Bsl) and 28-day before the SSC protocol. The rationale for collecting this sample 28-day before the SSC protocol was to allow for the seasonal decrease in serum $25(\mathrm{OH}) \mathrm{D}$ concentrations. The second blood draw was obtained immediately before (Pre) the SSC protocol. The six remaining blood draws were performed immediately (i.e., Post), 1-h, 24-h, 48-h, 72-h and 168-h (i.e., 7 days) after the SSC protocol. Subjects were familiarized with the single-leg peak isometric force testing procedure at Bsl. Thereafter, single-leg peak isometric force measurements were performed on six different occasions: (1) immediately before (Pre) the SSC protocol; and (2) immediately (Post); (3) 24-h; (4) 48-h; (5) 72-h and (6) 168-h after the SSC protocol.

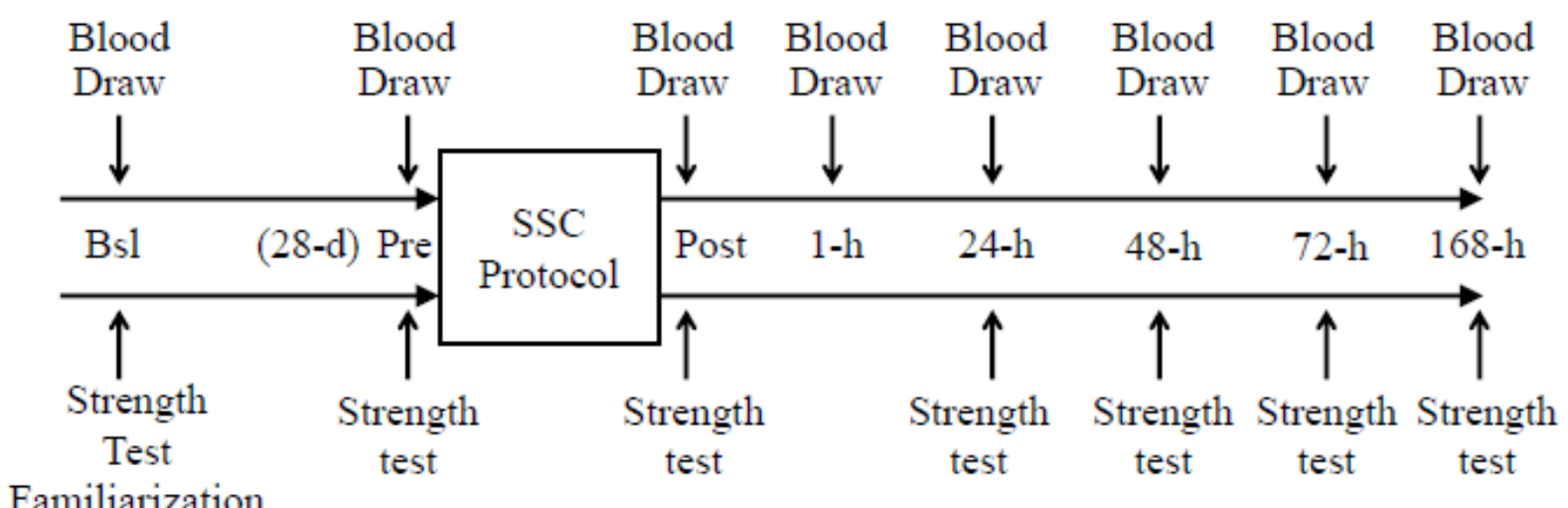

Familiarization 


\subsection{Analytical Procedures}

Blood draws were performed from the antecubital vein and collected in one $6.0 \mathrm{~mL}$ red-top serum Becton Dickinson (BD; Franklin Lake, NJ, USA) vacutainer tube, one $4.0 \mathrm{~mL}$ purple-top BD Vacutainer tube (K2 EDTA $7.2 \mathrm{mg}$ plasma), and one $4.5 \mathrm{~mL}$ light green-top BD Vacutainer tube (PST Gel and Lithium Heparin, 83 units). After coagulation, serum was separated by centrifugation (VWR International, Clinical 50 Centrifuge, Radnor, PA, USA) at $1100 \times \mathrm{g}$ for $20 \mathrm{~min}$ at room temperature. Serum samples were immediately aliquoted to several $500 \mu \mathrm{L}$ microcentrifuge tubes and stored at $-80{ }^{\circ} \mathrm{C}$ (Revco Freezer, GC Laboratory Equipment, Asheville, NC, USA) until the day of $25(\mathrm{OH}) \mathrm{D}$ and cytokine concentration analyses (see below). Plasma was separated by centrifugation (Heraeus Labofuge 400 series, Buckinghamshire, England) at $2400 \times g$ for $6 \mathrm{~min}$ at room temperature within $20 \mathrm{~min}$ of sample collection. Following separation, plasma samples were sent to ARUP Laboratories (Salt Lake City, UT, USA) for parathyroid hormone (PTH), calcium, albumin, aspartate aminotransferase (AST), and alanine aminotransferase (ALT) chemistries (see below).

\subsubsection{Serum 25(OH)D Concentration}

Serum $25(\mathrm{OH}) \mathrm{D}$ concentrations $(\mathrm{ng} / \mathrm{mL})$ were measured in duplicate (coefficient of variation $=3.19 \%$ ) at USANA Health Sciences, Inc. (Salt Lake City, UT, USA) [39]. Specifically, $100 \mu \mathrm{L}$ of serum was added to $400 \mu \mathrm{L}$ of a 2:1 methanol:chloroform solution containing deuterated $25(\mathrm{OH}) \mathrm{D}_{3}$ as an internal standard (10 ng/mL in the stock solution; $40 \mathrm{ng} / \mathrm{mL}$ final concentration) in a $2 \mathrm{~mL}$ centrifuge tube. Samples were immediately vortexed and allowed to sit on ice for $10 \mathrm{~min}$. Samples were then spun at $15,000 \times g$ for $5 \mathrm{~min}$ and the supernatant was transferred to a new $2 \mathrm{~mL}$ centrifuge tube containing $500 \mu \mathrm{L}$ of chloroform. Samples were vortexed and allowed to stand for $5 \mathrm{~min}$. To achieve phase separation, $750 \mu \mathrm{L}$ of $\mathrm{ddH}_{2} \mathrm{O}$ was added, vortexed, and centrifuged for $2 \mathrm{~min}$ at $15,000 \times g$. The aqueous phase (top), and any debris between the two phases, was removed and discarded. The remaining organic phase was dried down to completeness in a centrifugal vacuum concentrator for $18 \mathrm{~min}$ at $45^{\circ} \mathrm{C}$ under negative pressure. The pellet was then resuspended in $100 \mu \mathrm{L}$ of methanol and added to high performance-liquid chromatography (HPLC) vials.

Analytes were separated by injecting $10 \mu \mathrm{L}$ into an Agilent HPLC (series 6410, Model G6410B, Santa Clara, CA, USA) and a Phenomenex Inertsil 3 micron, $150 \times 4.60 \mathrm{~mm}$ column. Method conditions were: $0-8 \mathrm{~min}, 90 \% \mathrm{MeOH} / 10 \%(0.03 \%$ formic acid in water $) ; 8-15 \mathrm{~min}$, $100 \%$ 2-propanol; $15-20 \mathrm{~min}, 90 \% \mathrm{MeOH} / 10 \%$ (0.03\% formic acid in water). $25(\mathrm{OH}) \mathrm{D}_{2}$ and $25(\mathrm{OH}) \mathrm{D}_{3}$ were detected on an Agilent tandem mass spectrometer (Series 6410, Model G6410B, Santa Clara, CA, USA) using atmospheric pressure chemical ionization (APCI) detection $\left(350{ }^{\circ} \mathrm{C}\right.$ gas temperature, $400{ }^{\circ} \mathrm{C}$ vaporizer). The $25(\mathrm{OH}) \mathrm{D}_{3}$, deuterated $25(\mathrm{OH}) \mathrm{D}_{3}$, and $25(\mathrm{OH}) \mathrm{D}_{2}$ precursor ions were $383.3,386.3$, and 395.4 , respectively. The $25(\mathrm{OH}) \mathrm{D}_{3}$, deuterated $25(\mathrm{OH}) \mathrm{D}_{3}$, and $25(\mathrm{OH}) \mathrm{D}_{2}$ product ions were $365.3,368.3$, and 208.9 , respectively. Serum $25(\mathrm{OH}) \mathrm{D}_{2}$ and $25(\mathrm{OH}) \mathrm{D}_{3}$ concentrations were determined relative to authentic standards and corrected for recovery of the $25(\mathrm{OH}) \mathrm{D}_{3}$ internal standard. The detection limit was $<1 \mathrm{ng} / \mathrm{mL}$ for all analytes. The sum of $25(\mathrm{OH}) \mathrm{D}_{2}$ and $25(\mathrm{OH}) \mathrm{D}_{3}$ concentrations was used as the $25(\mathrm{OH}) \mathrm{D}$ total concentration. Serum $25(\mathrm{OH}) \mathrm{D}_{2}$ was not 
detected in any of the subjects, and therefore, serum $25(\mathrm{OH}) \mathrm{D}$ total concentrations are referred to as serum $25(\mathrm{OH}) \mathrm{D}$ concentrations hereafter.

\subsubsection{Serum Cytokine Concentrations}

Serum IFN- $\gamma$ and IL-4 were quantitated using a multiplexed sandwich capture assay developed in the ARUP Institute for Clinical and Experimental Pathology (University of Utah, Salt Lake City, UT, USA) using the Luminex Multi-Analyte Profiling system (Luminex, Austin, TX, USA) [72,73]. Monoclonal capture antibodies for IFN- $\gamma$ and IL-4 were coupled to microspheres (Luminex). The monoclonal antibody for IL-4 was purchased from Pharmingen/BD Biosciences (San Diego, CA, USA) and the monoclonal antibody for IFN- $\gamma$ was purchased from Biosciences (San Diego, CA, USA).

Standard curves for each cytokine were made using known concentrations of recombinant human cytokine of interest and performed during the same run as the subjects' serum analyses. All incubations were conducted at room temperature on an orbital plate shaker while protected from light for $10 \mathrm{~min}$. Following incubation, beads $(25 \mu \mathrm{L})$ were added to each well after 2 repeated bouts of vortexing $(10 \mathrm{~s})$ and sonication $(20 \mathrm{~s})$. The plate was then incubated for $1 \mathrm{~h}$, washed $3 \times$ by vacuum filtration with phosphate-buffered saline containing Tween 20 (PBST). Then, $100 \mu \mathrm{L}$ of a mixture of 2 different biotinylated secondary antibodies were added and incubated for $30 \mathrm{~min}$. Following washes (3×) with PBST, $100 \mu \mathrm{L} 5 \mu \mathrm{g}$ streptavidin-conjugated $R$-phycoerythrin/mL (Moss Substrates, Pasadena, MD, USA) were added to each well. Plates were incubated for $20 \mathrm{~min}$, washed $3 \times$ with PBST, then beads were re-suspended in $150 \mu \mathrm{L}$ PBST and mixed for $5 \mathrm{~min}$.

Microtiter plates were then placed in a Luminex 100 instrument for analysis. Microspheres pass through a flow cell where dual lasers identify the microsphere and quantitate the amount of analyte bound to the microsphere by measuring the median fluorescent intensity of the reporter molecule (phycyoerythrin). The median fluorescence intensity is then converted in $\mathrm{pg} / \mathrm{mL}$ based on the known concentrations of the standard curve.

\subsubsection{Clinical Chemistries}

Plasma AST (U/L), ALT (U/L), PTH (pg/mL), and calcium (mg/dL) concentrations were measured using a quantitative electrochemiluminescent immunoassay, and plasma albumin (g/dL) concentrations were determined using spectrophotometry (ARUP Laboratories, Salt Lake City, UT, USA).

\subsubsection{Single-Leg Strength Testing}

Single-leg strength testing was performed on a horizontal Plyo-Press (Athletic Republic, Park City, UT, USA). The reliability (intraclass reliability coefficients $=0.98$ ) for the peak isometric force measurement on the Plyo-Press has been reported previously [68] along with the testing procedures $[39,74]$. In brief, the Plyo-Press sled was adjusted for each subject to align the knee and hip joint flexion angles to $90^{\circ}$ with the abdominal, low back region secured and stabilized to the Plyo-Press sled with a harness. Hip and knee extension-isometric contractions were accomplished by overloading the weight stack resistance $(>2260 \mathrm{~N})$. Leg selection (i.e., CON or SSC leg) at the start of each testing session was randomized and followed by an alternating sequence of leg contractions. Peak 
isometric contractions on each leg were performed in triplicate (CON coefficient of variation $=3.62 \%$; $\mathrm{SSC}$ leg coefficient of variation $=4.70 \%$ ), and each isometric contraction was $3 \mathrm{~s}$ in duration and separated by $1 \mathrm{~min}$ of rest. Subjects were verbally instructed and strongly encouraged to exert maximal force against the mounted force platform during each isometric contraction. Force output was measured from signals obtained from a mounted force plate (Advanced Mechanical Technology, Watertown, MA, USA) on the Plyo-press. Data were sampled at $200 \mathrm{~Hz}$ with a low-pass filter at $10 \mathrm{~Hz}$ using DartPower software (Athletic Republic, Park City, UT, USA, version 2.0). Peak isometric force was defined as the highest resultant force produced from the three isometric tests and was expressed relative to body mass $(\mathrm{N} / \mathrm{kg})$.

\subsection{Statistical Analyses}

Data were checked for normality prior to all statistical analyses with a Kolmogorov-Smirnov test. Statistical significance of serum 25(OH)D, cytokine, PTH, AST, and ALT concentration data were assessed with a Friedman repeated measures analysis of variance (ANOVA) on ranks followed by a Tukey's Honestly Significant Difference (HSD) to test multiple pairwise comparisons. Statistical significance of calcium and albumin concentration data were assessed with a one-way ANOVA with repeated measures followed by a Tukey's HSD to test multiple pairwise comparisons. Statistical significance of the muscle strength data was assessed with a two-way (time, leg) ANOVA with repeated measures and followed by a Holm-Sidak method to test for multiple pairwise comparisons.

Separate multiple linear regression analyses were performed to determine if Pre serum 25(OH)D concentrations or the change in serum $25(\mathrm{OH}) \mathrm{D}$ concentrations from Bsl to Pre predict the immediate (i.e., Post) and persistent (i.e., 24-h, 48-h, and 72-h) deficits in muscle strength after a muscle-damaging event. Along with Pre serum 25(OH)D concentrations and the change in serum 25(OH)D concentrations from Bsl to Pre, body mass index and age were included as independent variables in the multiple linear regression model. Another multiple linear regression was performed to determine if circulating deviations in IFN- $\gamma$, calcium, PTH, or albumin predict serum $25(\mathrm{OH}) \mathrm{D}$ alterations. Prior to all multiple linear regressions, serum $25(\mathrm{OH}) \mathrm{D}$, IFN- $\gamma$, and PTH concentrations were rank transformed in order to achieve normality. Selection of independent variables for the multiple linear regression models were based on their biological significance on the dependent variable.

Secondary analyses consisted of a one (gender)-way ANOVA with repeated measures were performed to determine if a statistical difference existed between gender data (i.e., serum 25(OH)D, peak isometric force, peak isometric force difference between the CON and SSC legs at Post, 24-h, 48-h, and 72-h, AST, ALT, albumin, calcium, iPTH, IFN- $\gamma$ and IL-4). Statistical analyses were performed with SysStat software (SigmaPlot 10.0, SigmaStat 3.5, Chicago, IL, USA) and significance was set at a $p<0.05$. Data presented as mean \pm SEM, unless otherwise noted. 


\section{Results}

\subsection{Subject Characteristics}

Fourteen non-smoking subjects (male, $n=9$; female, $n=5$; age, $32 \pm 1$ year; height, $173 \pm 5 \mathrm{~cm}$; body mass, $79.0 \pm 4.8 \mathrm{~kg}$; body mass index, $26.1 \pm 0.9 \mathrm{~kg} / \mathrm{m}^{2}$ ) participated in this study. No subjects reported being highly trained, actively competing at a professional or amateur level, or performing recreational activities on a daily basis or for extended durations (i.e., $>60 \mathrm{~min}$ per session) consistently one year prior to study enrollment.

\subsection{Serum 25(OH)D Concentrations}

The average serum $25(\mathrm{OH}) \mathrm{D}$ concentration was $28.0 \pm 2.5 \mathrm{ng} / \mathrm{mL}$ upon study enrollment (Figure 3). Upon enrollment, five subjects $(36 \%)$ had a serum $25(\mathrm{OH}) \mathrm{D}$ concentration greater than $32 \mathrm{ng} / \mathrm{mL}$. Of the nine participants $(64 \%)$ with serum $25(\mathrm{OH}) \mathrm{D}$ concentrations less than $32 \mathrm{ng} / \mathrm{mL}$, three (21\%) subjects had a concentration less than $20 \mathrm{ng} / \mathrm{mL}$, and one $(7 \%)$ of which had a concentration less than $10 \mathrm{ng} / \mathrm{mL}$.

Figure 3. Serum 25(OH)D concentrations $(\mathrm{ng} / \mathrm{mL})$. Serum $25(\mathrm{OH}) \mathrm{D}$ concentrations were significantly increased at Bsl $\left({ }^{1} p<0.05 v s\right.$. Pre, 48-h, and 72-h) and Post $\left({ }^{2} p<0.05 v s\right.$. Pre, 24-h, 48-h, 72-h, and 168-h). Data presented as mean \pm SEM.

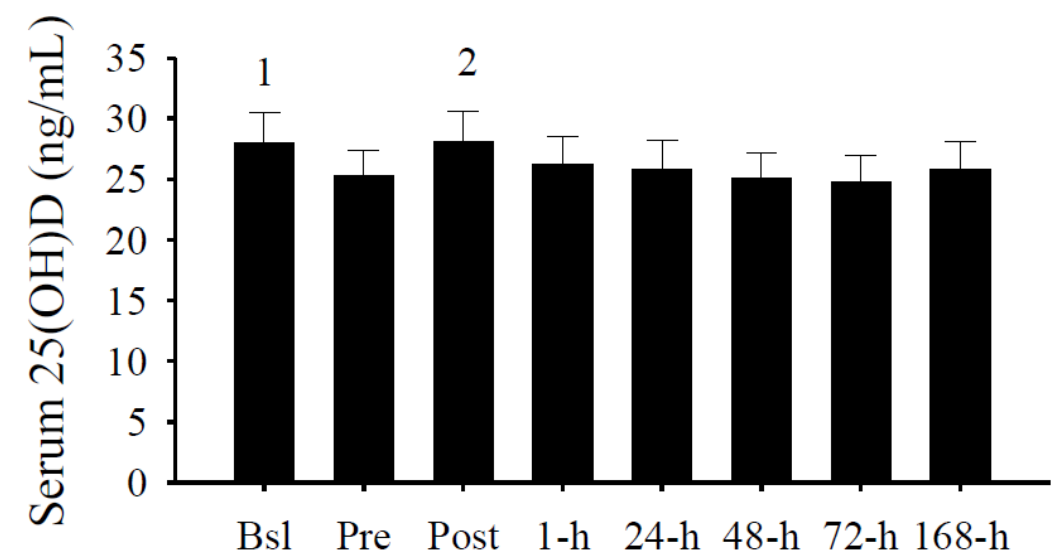

Consistent with the seasonal regulation [75], serum 25(OH)D concentrations significantly $(p<0.05)$ decreased by approximately $10 \%$ from Bsl to Pre (Figure 2). Surprisingly, serum 25(OH)D concentrations significantly $(p<0.05)$ increased immediately after the intense exercise protocol. Within minutes, however, serum $25(\mathrm{OH}) \mathrm{D}$ concentrations subsequently decreased $(p<0.05)$ and leveled during the following days.

\subsection{Peak Isometric Force}

Peak isometric force significantly $(p<0.05)$ decreased immediately and remained significantly $(p<0.05)$ impaired several days after the exercise protocol (Figure 4$)$. The immediate and persistent deficits in peak isometric force were apparent within the SSC leg across time $(p<0.05)$ and compared 
the corresponding CON leg $(p<0.05)$. At 168-h, peak isometric force returned to Pre and CON leg values.

Figure 4. Peak isometric force $(\mathrm{N} / \mathrm{kg})$. Single leg peak isometric forces were significantly (leg, time interaction, $p<0.05$ ) different following the SSC protocol. Single-leg peak isometric forces were not significantly different within the control (CON) leg across time, but within the SSC leg, decreased immediately ( ${ }^{1} p<0.05 v s$. Bsl, Pre, 24-h, 72-h, and 168-h) and remained impaired several days ( ${ }^{2} p<0.05$ vs. Bsl, Pre, and 168-h) after the intense exercise protocol. Peak isometric forces were also significantly $(* p<0.05)$ decreased in the SSC leg compared to those in the CON leg at Post, 24-h, 48-h, and 72-h. Data presented as mean $\pm \mathrm{SEM}$.

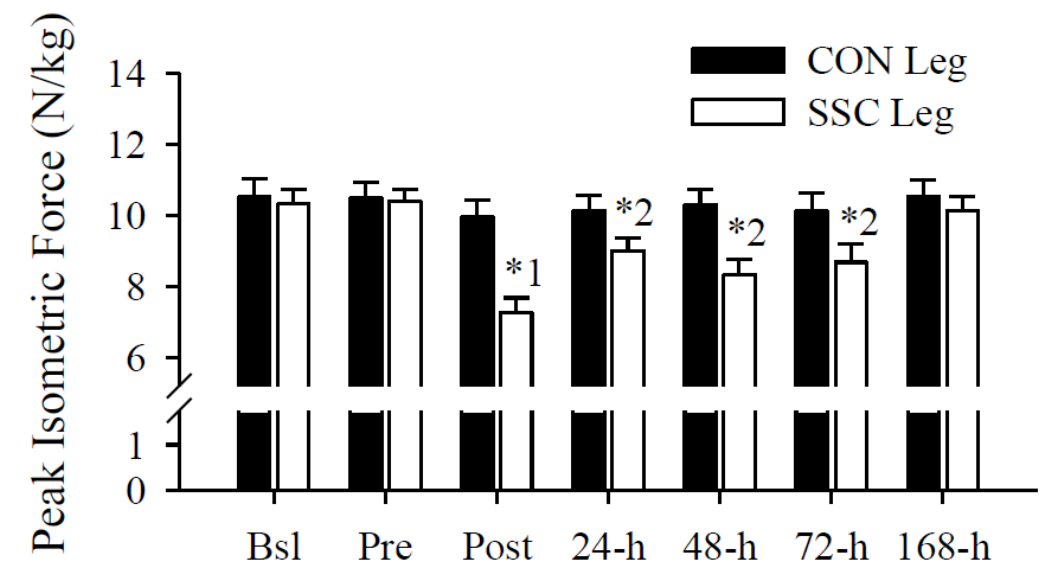

\subsection{Serum 25(OH)D Predicts Immediate and Persistent Muscular Weakness after a Muscle-Damaging Event}

Pre serum 25(OH)D concentrations significantly $(p<0.05)$ predicted muscular weakness $(\mathrm{CON} v s$. SSC Leg) immediately (i.e., Post) but not 24-h after the intense exercise protocol (Table 1). Serum $25(\mathrm{OH}) \mathrm{D}$ concentrations at Pre significantly $(p<0.05)$ predicted muscular weakness $(\mathrm{CON} v s$. SSC Leg) at 48-h and 72-h after the intense exercise protocol (Table 1).

In a sensitivity analysis, we repeated the multiple linear regression analyses (Table 1) regarding the prediction of muscular weakness following the intense exercise protocol. Excluding the $\Delta$ in Serum $25(\mathrm{OH}) \mathrm{D}$ from the multiple linear regression analyses did not change the significance of the models reported in Table 1. However, excluding the $\Delta$ in serum $25(\mathrm{OH}) \mathrm{D}$ increased the $p$-value from 0.04 to 0.08 for Pre serum $25(\mathrm{OH}) \mathrm{D}$ and decreased the model-statistical power from $86 \%$ to $59 \%$. It is likely that the shift in significance and decrease in statistical power at $72-\mathrm{h}$ after excluding the $\Delta$ in serum $25(\mathrm{OH}) \mathrm{D}$ from the multiple linear regression model is due to the size of our sample. 
Table 1. Higher serum $25(\mathrm{OH}) \mathrm{D}$ concentrations predict a lower deficit ${ }^{1}$ in muscle strength immediately (i.e., Post) and days (i.e., 48-h and 72-h) after intense exercise.

\begin{tabular}{|c|c|c|c|}
\hline & \multicolumn{2}{|c|}{ Coefficient } & \multirow[b]{2}{*}{$p$} \\
\hline & Unstandardized $( \pm \mathrm{SE})$ & Standardized & \\
\hline \multicolumn{4}{|c|}{ Post } \\
\hline Constant & $6.23( \pm 4.12)$ & & \\
\hline Pre serum 25(OH)D & $-0.28( \pm 0.11)$ & -0.68 & 0.03 \\
\hline$\Delta$ serum $25(\mathrm{OH}) \mathrm{D}$ & $-0.11( \pm 0.10)$ & -0.27 & 0.29 \\
\hline Age & $-0.06( \pm 0.08)$ & -0.17 & 0.50 \\
\hline BMI & $-0.28( \pm 0.13)$ & -0.57 & 0.06 \\
\hline \multicolumn{4}{|c|}{$r^{2}=0.51$, adjusted $r^{2}=0.30$} \\
\hline \multicolumn{4}{|c|}{$24-h$} \\
\hline Constant & $2.41( \pm 4.00)$ & & \\
\hline Pre serum 25(OH)D & $-0.17( \pm 0.10)$ & -0.52 & 0.14 \\
\hline$\Delta$ Serum $25(\mathrm{OH}) \mathrm{D}$ & $-0.04( \pm 0.10)$ & -0.12 & 0.70 \\
\hline Age & $-0.03( \pm 0.07)$ & -0.13 & 0.67 \\
\hline BMI & $-0.04( \pm 0.13)$ & -0.10 & 0.77 \\
\hline \multicolumn{4}{|c|}{$r^{2}=0.24$, adjusted $r^{2}=0.00$} \\
\hline \multicolumn{4}{|c|}{$48-h$} \\
\hline Constant & $7.24( \pm 4.43)$ & & \\
\hline Pre serum 25(OH)D & $-0.28( \pm 0.12)$ & -0.68 & 0.04 \\
\hline$\Delta$ Serum $25(\mathrm{OH}) \mathrm{D}$ & $-0.14( \pm 0.11)$ & -0.33 & 0.23 \\
\hline Age & $-0.07( \pm 0.08)$ & -0.23 & 0.40 \\
\hline BMI & $-0.10( \pm 0.11)$ & -0.29 & 0.33 \\
\hline \multicolumn{4}{|c|}{$r^{2}=0.45$, adjusted $r^{2}=0.21$} \\
\hline \multicolumn{4}{|c|}{$72-h$} \\
\hline Constant & $6.40( \pm 3.34)$ & & \\
\hline Pre serum 25(OH)D & $-0.21( \pm 0.09)$ & -0.63 & 0.04 \\
\hline$\Delta$ Serum 25(OH)D & $-0.15( \pm 0.08)$ & -0.45 & 0.09 \\
\hline Age & $-0.08( \pm 0.06)$ & -0.29 & 0.26 \\
\hline BMI & $-0.10( \pm 0.11)$ & -0.26 & 0.36 \\
\hline \multicolumn{4}{|c|}{$r^{2}=0.52$, adjusted $r^{2}=0.31$} \\
\hline
\end{tabular}

\subsection{Plasma AST and ALT}

Increases in circulating AST and ALT are indices of skeletal muscle damage [76,77]. Days after the exercise protocol, plasma AST (Figure 5A) and ALT (Figure 5B) concentrations were significantly (both $p<0.05$ ) increased, thereby imply the presence of skeletal muscle damage. 
Figure 5. Plasma aspartate aminotransferase (AST) (U/L) and ALT (U/L) concentrations. (A) Plasma AST was significantly increased at $72-\mathrm{h}\left({ }^{1} p<0.05 v s\right.$. Bsl). (B) Plasma ALT was significantly $\left({ }^{2} p<0.05 v s\right.$. Post $)$ increased at $24-\mathrm{h}, 72-\mathrm{h}$, and $168-\mathrm{h}$. Data presented as mean \pm SEM.
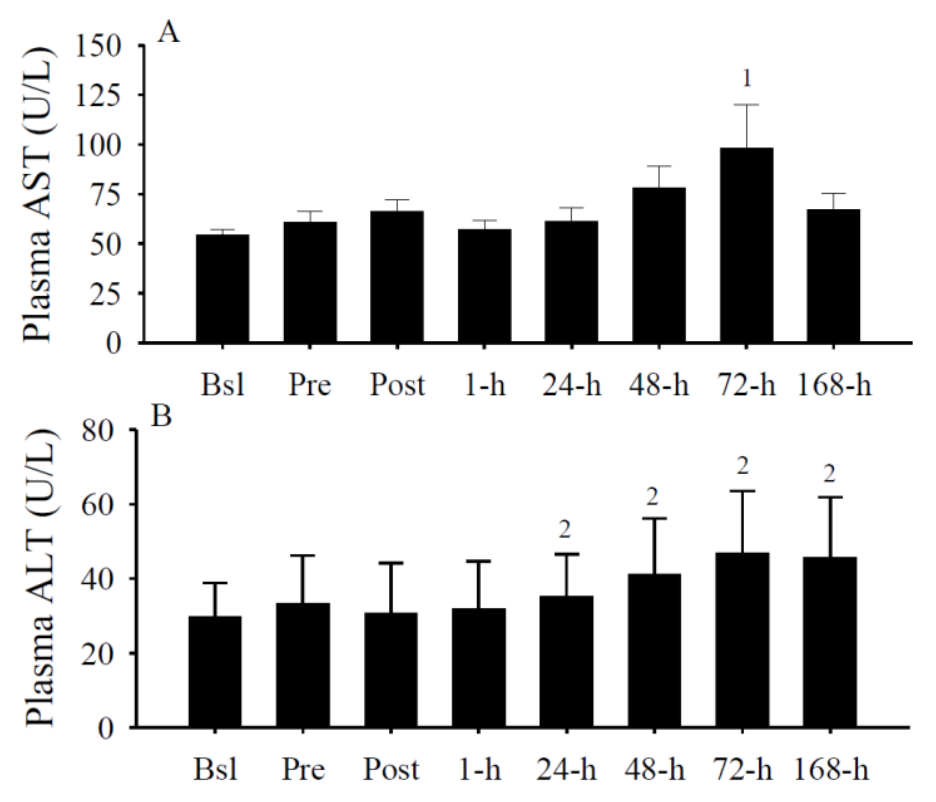

\subsection{Serum Cytokine Concentrations}

Serum IFN- $\gamma$ concentrations (Figure 6A) were significantly $(p<0.05)$ increased immediately after the exercise protocol. Although serum IL-4 concentrations were also elevated (Figure 6B), concentrations were not significantly different. Thus, IFN- $\gamma$ was elevated while IL-4 was not significantly changed immediately after intense exercise.

Figure 6. Serum IFN- $\gamma$ and IL-4 concentrations $(\mathrm{pg} / \mathrm{mL})$. Serum IFN- $\gamma$ concentrations (A) were significantly ( ${ }^{1} p<0.05$ vs. 1 -h, 48 -h, and 72-h) increased at Post. Serum IL-4 concentrations $(\mathbf{B})$ were not significantly different. Data presented as mean $\pm \mathrm{SEM}$.
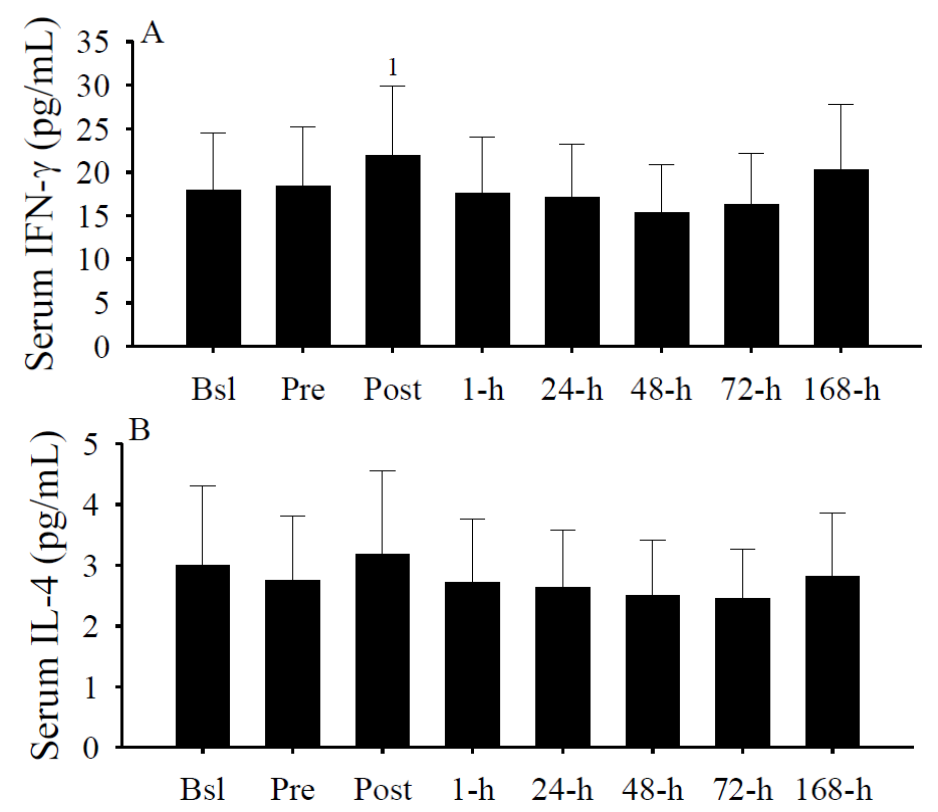


\subsection{Plasma Calcium, PTH, and Albumin Concentrations}

Immediately following the exercise protocol (i.e., Post), plasma calcium (Figure 7A) and PTH (Figure 7B) concentrations were significantly (both $p<0.05$ ) increased. At 1-h, calcium concentrations remained significantly $(p<0.05)$ increased and plasma PTH concentrations significantly $(p<0.05)$ decreased. Immediately following intense exercise, albumin concentrations significantly $(p<0.05)$ increased (Figure 7C).

Figure 7. Plasma calcium (mg/dL), parathyroid hormone (PTH; pg/mL), and albumin (g/dL) concentrations. (A) Total plasma calcium concentrations were significantly increased at Post ( ${ }^{1} p<0.05$ vs. Bsl, Pre, 24-h, 48-h, 72-h, and 168-h) and 1-h $\left({ }^{2} p<0.05\right.$ vs. 24-h, 48-h, 72-h, and 168-h). (B) Plasma PTH concentrations were significantly increased at Post ( ${ }^{3} p<0.05 v s$. Bsl, Pre, 1-h, and 72-h) and significantly decreased at 1-h $\left({ }^{4} p<0.05\right.$ vs. 24-h, 48-h, and 168-h). (C) Plasma albumin concentrations were significantly increased at Post $\left({ }^{5} p<0.05\right.$ vs. Bsl, Pre, 1-h, 24-h, 48-h, 72-h, and 168-h). Data presented as mean $\pm \mathrm{SEM}$.

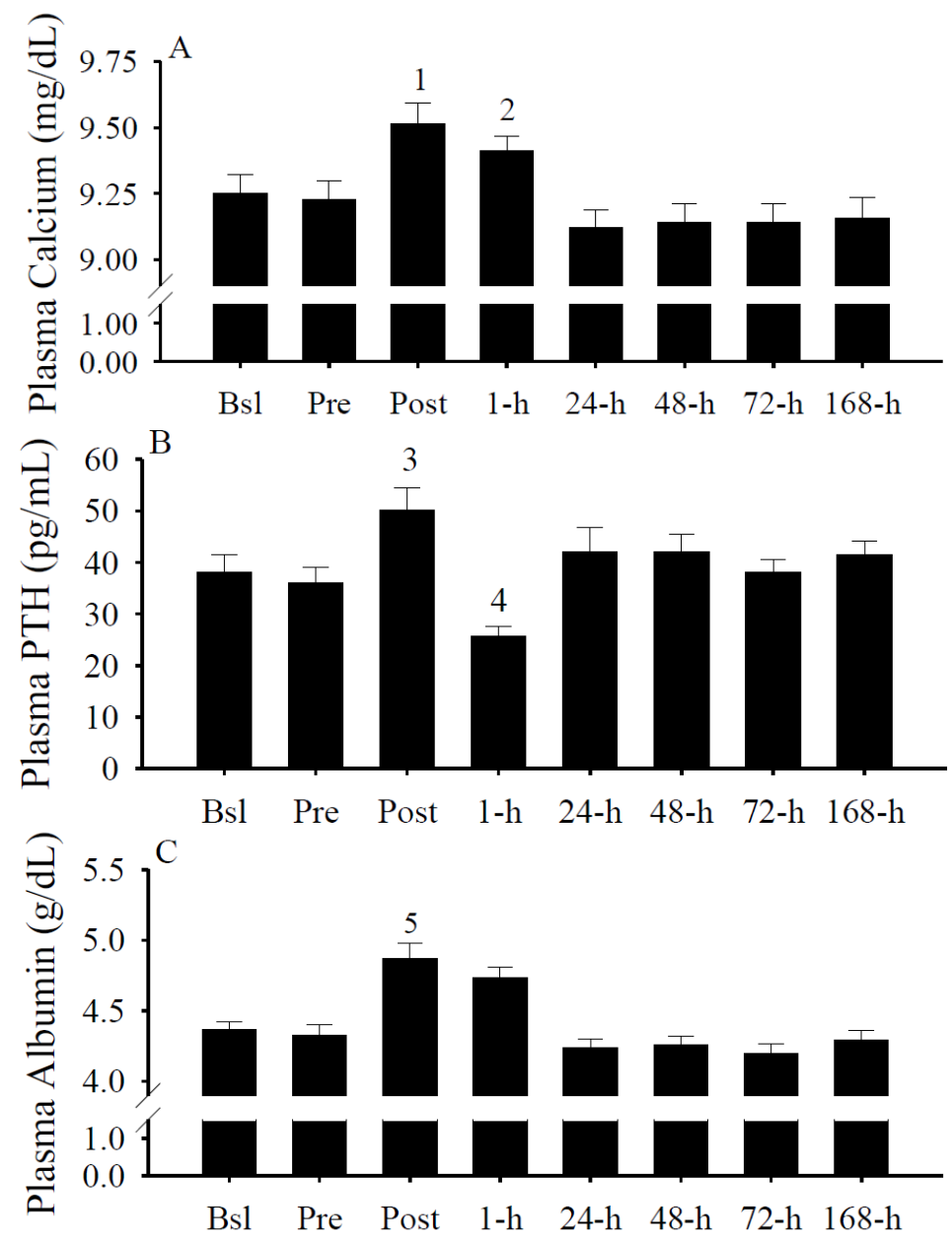

\subsection{IFN- $\gamma$ and Albumin Predict Serum 25(OH)D Changes}

Circulating IFN- $\gamma$ increases predicted $(p<0.001)$ serum $25(\mathrm{OH}) \mathrm{D}$ decreases, while albumin increases predicted $(p<0.005)$ serum $25(\mathrm{OH}) \mathrm{D}$ increases (Table 2$)$. 
Table 2. Circulating albumin increases predict serum $25(\mathrm{OH}) \mathrm{D}$ increases, while IFN- $\gamma$ increases predict serum $25(\mathrm{OH}) \mathrm{D}$ decreases.

\begin{tabular}{cccc}
\hline & \multicolumn{2}{c}{ Coefficient } & \\
\cline { 2 - 3 } & Unstandardized $( \pm$ SE) & Standardized & $p$ \\
\hline Constant & $75.99( \pm 6.32)$ & & \\
$\Delta$ IFN- $\gamma$ & $-0.60( \pm 0.09)$ & -0.60 & $<0.001$ \\
$\Delta$ iPTH & $0.06( \pm 0.09)$ & 0.06 & 0.48 \\
$\Delta$ Calcium & $19.7( \pm 10.6)$ & 0.19 & 0.07 \\
$\Delta$ Albumin & $28.1( \pm 9.3)$ & 0.32 & $<0.005$ \\
& $r^{2}=0.36$, adjusted $r^{2}=0.33$ & & \\
\hline
\end{tabular}

$\Delta$, change from Bsl.

\subsection{Gender Differences}

In the secondary analysis investigating the difference between genders, serum $25(\mathrm{OH}) \mathrm{D}$, IFN- $\gamma$, IL-4, PTH, AST, ALT, peak isometric force, and the difference in peak isometric force between the CON and SSC legs were not significantly different between males and females (data not shown). However, circulating calcium (males, $9.33 \pm 0.06$ vs. females, $9.09 \pm 0.08 \mathrm{mg} / \mathrm{dL}$ ) and albumin (males, $4.48 \pm 0.05 v s$. females, $4.16 \pm 0.07 \mathrm{~g} / \mathrm{dL}$ ) concentrations were significantly (both $p<0.05$ ) different between genders.

\section{Discussion}

In the present investigation, we provide new data identifying that muscular weakness immediately (i.e., Post) and several days (i.e., 48-h and 72-h) after intense exercise were inversely predicted by pre-exercise serum $25(\mathrm{OH}) \mathrm{D}$ concentrations. Additionally, IFN- $\gamma$ increases predicted serum $25(\mathrm{OH}) \mathrm{D}$ decreases, while albumin increases predicted serum $25(\mathrm{OH}) \mathrm{D}$ increases. These unique findings establish the importance of IFN- $\gamma$ and albumin on the regulation of serum $25(\mathrm{OH}) \mathrm{D}$, and that the serum $25(\mathrm{OH}) \mathrm{D}$ concentration prior to exercise could be a determinant of muscular strength after intense exercise.

The novel finding of the present investigation was the inverse association between pre-exercise serum 25(OH)D and both immediate and persistent muscular weakness after intense exercise. Pre-exercise serum 25(OH)D concentrations, however, did not predict muscular weakness 24-h after the intense exercise protocol, collectively suggesting a temporal sensitivity of skeletal muscle strength to vitamin D levels following muscular insult.

Muscular weakness is a unique measure of muscle recovery because it spans the degenerative and regenerative events occurring at the molecular and cellular levels [44]. Furthermore, muscular weakness persists until repair is complete, suggesting that a faster recovery in skeletal muscle strength reflects a faster progression through the degenerative and regenerative events following muscular insult. In experimental rats, vitamin D treatment accelerated the recovery in muscular strength after injury [19]. Vitamin D treatment also increased serum 25(OH)D concentrations [19], which presumably, maintained substrate availability for the conversion of vitamin $\mathrm{D}$ to $1,25(\mathrm{OH}) \mathrm{D}$ and increased the expression (message and protein) of the vitamin D-receptor (VDR) [21]. Despite cell and 
experimental animal data supporting the therapeutic influence of vitamin D on the muscle recovery after muscular insult, results in human suggest otherwise.

Contrasting with the results here, Ring et al. [55] reported that vitamin D status was not influential on muscular weakness after exercise. The reason for the conflicting reports could relate to different experimental protocols, including the muscle(s) or muscle group(s) exercised, damaged and/or tested, disparate contraction modalities (i.e., eccentric vs. eccentric-concentric contraction cycles), or the volume, duration and intensity of the exercise protocol. Additionally, the non-significant linear regression reported previously consisted of $2-\mathrm{d}$ post isometric force and serum $25(\mathrm{OH}) \mathrm{D}$ concentration data [55]. Although we did not observe a significant difference 48-h after the intense exercise protocol, it is probable that serum $25(\mathrm{OH}) \mathrm{D}$ concentrations were modulated by intense-eccentric contractions [55], and consequentially, confounded the interpretation between vitamin D and muscular strength. To avoid the potential confounding influence of exercise in the present study, pre-exercise serum $25(\mathrm{OH}) \mathrm{D}$ concentrations were related to post-exercise muscle weakness.

Consistent with the postulate that exercise modulates circulating vitamin $\mathrm{D}$, we identify a transient $25(\mathrm{OH}) \mathrm{D}$ increase in the circulation immediately after intense exercise. The serum $25(\mathrm{OH}) \mathrm{D}$ concentration increases immediately after the intense exercise protocol was preceded by an initial (i.e., Bsl to Pre) and followed by a second (i.e., Post to 1-h) decrease. The initial decrease is consistent with data demonstrating the serum $25(\mathrm{OH}) \mathrm{D}$ concentration response during the winter [75]. The second decrease, however, suggests that serum $25(\mathrm{OH}) \mathrm{D}$ is temporally sensitive to intense exercise. Interestingly, cytokine and protein shifts in the circulation could contribute, in part, to the observed 25(OH)D fluctuations (see Table 2).

Interferon $\gamma$ is an inflammatory cytokine that regulates vitamin D metabolism $[60,61,78,79]$. In immune and endothelial cells, IFN- $\gamma$ impairs CYP27A1 message and protein expression [80], and thereby implying its potential role of impeding $25(\mathrm{OH}) \mathrm{D}$ production. Furthermore, IFN- $\gamma$ accelerates the conversion of $25(\mathrm{OH}) \mathrm{D}$ to $1,25(\mathrm{OH}) \mathrm{D}[60,61,78,79]$ by increasing $1 \alpha \mathrm{OHase}$ expression $[62,64,65,81,82]$. Supporting the influence of IFN- $\gamma$ on vitamin D metabolism in vivo, we illustrated previously that IFN- $\gamma$ tends to inversely correlate with $25(\mathrm{OH}) \mathrm{D}$ and significantly correlates (positive) with 1,25(OH)D [59], suggesting 25(OH)D decreases and 1,25(OH)D increases with increasing IFN- $\gamma$ in the circulation. Based on the results here and those reported elsewhere, we propose that IFN- $\gamma$ contributes to the circulating $25(\mathrm{OH}) \mathrm{D}$ decrease by impairing the production and accelerating the catabolism of $25(\mathrm{OH}) \mathrm{D}$. However, confirmation of the proposed hypothesis requires further investigation.

Interleukin-4 is another inflammatory cytokine that has been implicated in the regulation of vitamin D metabolism. In human monocytes, IL-4 upregulated the message expression of CYP27B1 and the VDR [65]. Although message expression increased, IL-4 did not increase the activity of CYP27B1 [65]. Strikingly, IL-4 increased the activity of CYP24A1 and the conversion of $25(\mathrm{OH}) \mathrm{D}$ to $24,25(\mathrm{OH}) \mathrm{D}$ in monocytes [65]. These unique findings suggest that IL-4 could decrease $25(\mathrm{OH}) \mathrm{D}$ concentrations by accelerating catabolism. However, we were unable to detect a significant difference in IL-4 concentrations prior to or following the intense exercise protocol. Thus, based on our findings, it is unclear if IL-4 contributes to the fluctuating serum $25(\mathrm{OH}) \mathrm{D}$ concentrations observed during the winter and following intense exercise. 
Another unique finding of the present investigation was the prediction of serum $25(\mathrm{OH}) \mathrm{D}$ concentrations by albumin. Albumin is a plasma protein synthesized in the liver that maintains colloid osmotic pressure [83]. Following short-term, high intensity exercise, albumin increases in the circulation and expands blood volume [84-86]. In the circulation, albumin binds to vitamin D metabolites [87]. The predication of increasing $25(\mathrm{OH}) \mathrm{D}$ by albumin is plausibly the product of increased hepatic secretion of albumin and its binding to vitamin D in the blood. However, additional research investigating the influence of albumin on vitamin D concentration in the circulation is required.

Calcium and PTH regulate circulating 25(OH)D concentrations. Low calcium concentrations in the blood stimulate the parathyroid gland to secrete PTH. The increase in PTH stimulates the conversion of $25(\mathrm{OH}) \mathrm{D}$ to $1,25(\mathrm{OH}) \mathrm{D}$ [88-90] and increases the circulating calcium. Increases in dietary and serum calcium increase the catabolism of $25(\mathrm{OH}) \mathrm{D}$ to $24,25(\mathrm{OH}) \mathrm{D}$ [91]. In this investigation, we found an increase in plasma calcium concentrations immediately following the intense exercise protocol that was resolved by the following day (Figure 7A). PTH concentrations displayed a transient fluctuation after (i.e., Post and 1-h) the intense exercise protocol (Figure 7B). Although vitamin D metabolism is regulated by calcium and PTH, neither the calcium or PTH predicted the deviation in serum 25(OH)D concentrations after intense exercise (Table 2).

In addition to those discussed above, there are limitations to this study that should be considered with future investigations. First, we did not obtain skeletal muscle biopsies to assess local damage, vitamin D metabolites, or the enzymes involved with vitamin D metabolism. Second, we did not control fluid or dietary intake prior to, during, or following intense exercise. Third, it is unknown if the results here can be extrapolated to other inflammatory modalities. Fourth, calcium and albumin concentrations were significantly different between genders. Calcium and albumin concentrations, however, were within the recommended clinical reference ranges (calcium, 8.4-10.4 mg/dL; albumin, 3.3-4.8 g/dL) for both genders, and therefore, it is unclear if this statistical difference is of physiological impact. Along these lines, serum 25(OH)D concentrations and peak isometric forces were not significantly different between male and female subjects as well. Next, this study consisted of 14 subject's total. Future investigations are encouraged to include larger sample sizes when investigating the potential influence of vitamin D on skeletal muscle strength after injury. Finally, it is unknown skeletal muscle damage or fatigue-related factors, or both, were contributing to muscular weakness after the imposed exercise protocol. However, it is noteworthy that circulating biomarkers of skeletal muscle damage, and specifically AST and ALT, were elevated concurrently with deficits in skeletal muscle strength during the days following the intense exercise protocol. Thus, these results tend to support the possibility of the presence of skeletal muscle damage.

\section{Conclusions and Implications}

Muscle weakness hinders millions of people worldwide every year and is mediated by a variety of conditions, including aging, disease, inactivity, limb immobilization, repetitive use, and intense or unaccustomed exercise. In the present investigation, we reveal that muscular weakness after an intense exercise bout is abrogated with increasing serum $25(\mathrm{OH}) \mathrm{D}$ concentration prior to exercise. However, this was apparent immediately and several days (2-day and 3-day), but not 1-day, after intense exercise. Additionally, IFN- $\gamma$ and albumin predicted serum $25(\mathrm{OH}) \mathrm{D}$ concentration fluctuations, and 
due on these fluctuations, we recommend caution when interpreting serum $25(\mathrm{OH}) \mathrm{D}$ concentrations immediately after intense exercise and/or during an acute inflammatory response. We conclude that maintaining an adequate serum $25(\mathrm{OH}) \mathrm{D}$ concentration could attenuate muscular weakness after intense exercise. Given the feasibility of increasing $25(\mathrm{OH}) \mathrm{D}$ concentrations in the blood, future research investigating the influence of diverse vitamin $\mathrm{D}$ interventions on the alleviation of muscular weakness after muscular insult are encouraged in humans.

\section{Acknowledgments}

We would like to thank the subjects who participated in this study; Penny Snow, Kristi Thunell and Michelle (Shelly) Oliver (The Orthopedic Specialty Hospital) for the phlebotomy; and the late Adam S. Dern (USANA Health Sciences, Inc.) for serum sample preparations. This study was funded in part by the Intermountain Research and Medical Foundation (Intermountain Healthcare, Salt Lake City, UT, USA) and the ARUP Institute for Clinical and Experimental Pathology (Salt Lake City, UT, USA).

\section{Conflict of Interest}

The authors declare no conflict of interest.

\section{References}

1. Jones, G. Pharmacokinetics of vitamin D toxicity. Am. J. Clin. Nutr. 2008, 88, 582S-586S.

2. Girgis, C.M.; Clifton-Bligh, R.J.; Hamrick, M.W.; Holick, M.F.; Gunton, J.E. The roles of vitamin D in skeletal muscle: form, function, and metabolism. Endocr. Rev. 2013, 34, 33-83.

3. Ceglia, L.; Harris, S.S. Vitamin D and its role in skeletal muscle. Calcif. Tissue Int. 2013, 92, $151-162$.

4. Bischoff-Ferrari, H.; Stahelin, H.B.; Walter, P. Vitamin D effects on bone and muscle. Int. J. Vitam. Nutr. Res. 2011, 81, 264-272.

5. Ceglia, L. Vitamin D and skeletal muscle tissue and function. Mol. Aspects Med. 2008, 29, 407-414.

6. Boland, R.L. VDR activation of intracellular signaling pathways in skeletal muscle. Mol. Cell. Endocrinol. 2011, 347, 11-16.

7. Boland, R. Role of vitamin D in skeletal muscle function. Endocr. Rev. 1986, 7, 434-448.

8. Boland, R.; de Boland, A.R.; Marinissen, M.J.; Santillan, G.; Vazquez, G.; Zanello, S. Avian muscle cells as targets for the secosteroid hormone 1,25-dihydroxy-vitamin D3. Mol. Cell. Endocrinol. 1995, 114, 1-8.

9. Birge, S.J.; Haddad, J.G. 25-Hydroxycholecalciferol stimulation of muscle metabolism. J. Clin. Invest. 1975, 56, 1100-1107.

10. De Boland, A.R.; Boland, R. In vitro cellular muscle calcium metabolism. Characterization of effects of 1,25-dihydroxy-vitamin D3 and 25-hydroxy-vitamin D3. Z. Naturforsch. C 1985, 40, 102-108. 
11. De Boland, A.R.; Boland, R.L. Rapid changes in skeletal muscle calcium uptake induced in vitro by 1,25-dihydroxyvitamin D3 are suppressed by calcium channel blockers. Endocrinology 1987, $120,1858-1864$.

12. Walters, M.R.; Ilenchuk, T.T.; Claycomb, W.C. 1,25-Dihydroxyvitamin D3 stimulates 45Ca2+ uptake by cultured adult rat ventricular cardiac muscle cells. J. Biol. Chem. 1987, 262, 2536-2541.

13. Giuliani, D.L.; Boland, R.L. Effects of vitamin D3 metabolites on calcium fluxes in intact chicken skeletal muscle and myoblasts cultured in vitro. Calcif. Tissue Int. 1984, 36, 200-205.

14. Matthews, C.; Heimberg, K.W.; Ritz, E.; Agostini, B.; Fritzsche, J.; Hasselbach, W. Effect of 1,25-dihydroxycholecalciferol on impaired calcium transport by the sarcoplasmic reticulum in experimental uremia. Kidney Int. 1977, 11, 227-235.

15. Morelli, S.; Buitrago, C.; Vazquez, G.; de Boland, A.R.; Boland, R. Involvement of tyrosine kinase activity in 1alpha,25(OH)2-vitamin D3 signal transduction in skeletal muscle cells. J. Biol. Chem. 2000, 275, 36021-36028.

16. Selles, J.; Boland, R. Rapid stimulation of calcium uptake and protein phosphorylation in isolated cardiac muscle by 1,25-dihydroxyvitamin D3. Mol. Cell. Endocrinol. 1991, 77, 67-73.

17. Buitrago, C.; Boland, R.; de Boland, A.R. The tyrosine kinase c-Src is required for 1,25(OH)2-vitamin D3 signalling to the nucleus in muscle cells. Biochim. Biophys. Acta 2001, 1541, 179-187.

18. Buitrago, C.G.; Arango, N.S.; Boland, R.L. 1alpha,25(OH)2D3-dependent modulation of Akt in proliferating and differentiating $\mathrm{C} 2 \mathrm{C} 12$ skeletal muscle cells. J. Cell. Biochem. 2012, 113, 1170-1181.

19. Stratos, I.; Li, Z.; Herlyn, P.; Rotter, R.; Behrendt, A.K.; Mittlmeier, T.; Vollmar, B. Vitamin D increases cellular turnover and functionally restores the skeletal muscle after crush injury in rats. Am. J. Pathol. 2012, 182, 895-904.

20. Alami-Durante, H.; Cluzeaud, M.; Bazin, D.; Mazurais, D.; Zambonino-Infante, J.L. Dietary cholecalciferol regulates the recruitment and growth of skeletal muscle fibers and the expressions of myogenic regulatory factors and myosin heavy chain in European sea bass larvae. J. Nutr. 2011, 141, 2146-2151.

21. Srikuea, R.; Zhang, X.; Park-Sarge, O.K.; Esser, K.A. VDR and CYP27B1 are expressed in $\mathrm{C} 2 \mathrm{C} 12$ cells and regenerating skeletal muscle: Potential role in suppression of myoblast proliferation. Am. J. Physiol. Cell. Physiol. 2012, 303, C396-C405.

22. Garcia, L.A.; Ferrini, M.G.; Norris, K.C.; Artaza, J.N. 1,25(OH)(2)vitamin D(3) enhances myogenic differentiation by modulating the expression of key angiogenic growth factors and angiogenic inhibitors in $\mathrm{C}(2) \mathrm{C}(12)$ skeletal muscle cells. J. Steroid. Biochem. Mol. Biol. 2013, 133, 1-11.

23. Ward, K.A.; Das, G.; Berry, J.L.; Roberts, S.A.; Rawer, R.; Adams, J.E.; Mughal, Z. Vitamin D status and muscle function in post-menarchal adolescent girls. J. Clin. Endocrinol. Metab. 2009, 94, 559-563.

24. Ward, K.A.; Das, G.; Roberts, S.A.; Berry, J.L.; Adams, J.E.; Rawer, R.; Mughal, M.Z. A randomized, controlled trial of vitamin D supplementation upon musculosketal health in postmenarchal females. J. Clin. Endocrinol. Metab. 2010, 95, 4643-4651. 
25. Foo, L.H.; Zhang, Q.; Zhu, K.; Ma, G.; Hu, X.; Greenfield, H.; Fraser, D.R. Low vitamin D status has an adverse influence on bone mass, bone turnover, and muscle strength in Chinese adolescent girls. J. Nutr. 2009, 139, 1002-1007.

26. Ceglia, L.; Chiu, G.R.; Harris, S.S.; Araujo, A.B. Serum 25-hydroxyvitamin D concentration and physical function in adult men. Clin. Endocrinol. (Oxf.) 2011, 74, 370-376.

27. Ziambaras, K.; Dagogo-Jack, S. Reversible muscle weakness in patients with vitamin D deficiency. West. J. Med. 1997, 167, 435-439.

28. Russell, J.A. Osteomalacic myopathy. Muscle Nerve 1994, 17, 578-580.

29. Stockton, K.A.; Kandiah, D.A.; Paratz, J.D.; Bennell, K.L. Fatigue, muscle strength and vitamin D status in women with systemic lupus erythematosus compared to healthy controls. Lupus 2011, 21, 271-278.

30. Glerup, H.; Mikkelsen, K.; Poulsen, L.; Hass, E.; Overbeck, S.; Andersen, H.; Charles, P.; Eriksen, E.F. Hypovitaminosis D myopathy without biochemical signs of osteomalacic bone involvement. Calcif. Tissue Int. 2000, 66, 419-424.

31. Barker, T.; Martins, T.B.; Hill, H.R.; Kjeldsberg, C.R.; Trawick, R.H.; Weaver, L.K.; Traber, M.G. Low vitamin D impairs strength recovery after anterior cruciate ligament surgery. J. Evid. Based Complement. Altern. Med. 2011, 16, 201-209.

32. Prineas, J.W.; Mason, A.S.; Henson, R.A. Myopathy in metabolic bone disease. Br. Med. J. 1965, $1,1034-1036$.

33. Gordon, P.L.; Doyle, J.W.; Johansen, K.L. Association of 1,25-dihydroxyvitamin D levels with physical performance and thigh muscle cross-sectional area in chronic kidney disease stage 3 and 4. J. Ren. Nutr. 2012, 22, 423-433.

34. Grimaldi, A.S.; Parker, B.A.; Capizzi, J.A.; Clarkson, P.M.; Pescatello, L.S.; White, C.M.; Thompson, P.D. 25(OH) vitamin D is associated with greater muscle strength in healthy men and women. Med. Sci. Sports Exerc. 2013, 45, 157-162.

35. Von Hurst, P.R.; Conlon, C.; Foskett, A. Vitamin D status predicts hand-grip strength in young adult women living in Auckland, New Zealand. J. Steroid. Biochem. Mol. Biol. 2012, doi:10.1016/j.jsbmb.2012.11.015.

36. Wicherts, I.S.; van Schoor, N.M.; Boeke, A.J.; Visser, M.; Deeg, D.J.; Smit, J.; Knol, D.L.; Lips, P. Vitamin D status predicts physical performance and its decline in older persons. J. Clin. Endocrinol. Metab. 2007, 92, 2058-2065.

37. Barker, T.; Martins, T.B.; Hill, H.R.; Kjeldsberg, C.R.; Dixon, B.M.; Schneider, E.D.; Henridsen, V.T.; Weaver, L.K. Circulating pro-inflammatory cytokines are elevated and peak power output correlates with 25-hydroxyvitamin D in vitamin D insufficient adults. Eur. J. Appl. Physiol. 2013, doi:10.1007/s00421-012-2582-7.

38. Carrillo, A.E.; Flynn, M.G.; Pinkston, C.; Markofski, M.M.; Jiang, Y.; Donkin, S.S.; Teegarden, D. Impact of vitamin D supplementation during a resistance training intervention on body composition, muscle function, and glucose tolerance in overweight and obese adults. Clin. Nutr. 2012, doi:10.1016/j.clnu.2012.08.014. 
39. Barker, T.; Martins, T.B.; Hill, H.R.; Kjeldsberg, C.R.; Henriksen, V.T.; Dixon, B.M.; Schneider, E.D.; Dern, A.; Weaver, L.K. Different doses of supplemental vitamin D maintain interleukin-5 without altering skeletal muscle strength: A randomized, double-blind, placebo-controlled study in vitamin D sufficient adults. Nutr. Metab. (Lond.) 2012, 9, 16.

40. Sato, Y.; Iwamoto, J.; Kanoko, T.; Satoh, K. Low-dose vitamin D prevents muscular atrophy and reduces falls and hip fractures in women after stroke: A randomized controlled trial. Cerebrovasc. Dis. 2005, 20, 187-192.

41. Janssen, H.C.; Samson, M.M.; Verhaar, H.J. Muscle strength and mobility in vitamin D-insufficient female geriatric patients: A randomized controlled trial on vitamin D and calcium supplementation. Aging Clin. Exp. Res. 2010, 22, 78-84.

42. Verhaar, H.J.; Samson, M.M.; Jansen, P.A.; de Vreede, P.L.; Manten, J.W.; Duursma, S.A. Muscle strength, functional mobility and vitamin D in older women. Aging (Milano) 2000, 12, 455-460.

43. Floyd, M.; Ayyar, D.R.; Barwick, D.D.; Hudgson, P.; Weightman, D. Myopathy in chronic renal failure. Q. J. Med. 1974, 43, 509-524.

44. Warren, G.L.; Lowe, D.A.; Armstrong, R.B. Measurement tools used in the study of eccentric contraction-induced injury. Sports Med. 1999, 27, 43-59.

45. Komi, P.V. Stretch-shortening cycle: A powerful model to study normal and fatigued muscle. J. Biomech. 2000, 33, 1197-1206.

46. Burgi, A.A.; Gorham, E.D.; Garland, C.F.; Mohr, S.B.; Garland, F.C.; Zeng, K.; Thompson, K.; Lappe, J.M. High serum 25-hydroxyvitamin D is associated with a low incidence of stress fractures. J. Bone Miner. Res. 2011, 26, 2371-2377.

47. Lappe, J.; Cullen, D.; Haynatzki, G.; Recker, R.; Ahlf, R.; Thompson, K. Calcium and vitamin D supplementation decreases incidence of stress fractures in female navy recruits. J. Bone Miner. Res. 2008, 23, 741-749.

48. Snijder, M.B.; van Schoor, N.M.; Pluijm, S.M.; van Dam, R.M.; Visser, M.; Lips, P. Vitamin D status in relation to one-year risk of recurrent falling in older men and women. J. Clin. Endocrinol. Metab. 2006, 91, 2980-2985.

49. Broe, K.E.; Chen, T.C.; Weinberg, J.; Bischoff-Ferrari, H.A.; Holick, M.F.; Kiel, D.P. A higher dose of vitamin D reduces the risk of falls in nursing home residents: A randomized, multiple-dose study. J. Am. Geriatr. Soc. 2007, 55, 234-239.

50. Bischoff, H.A.; Stahelin, H.B.; Dick, W.; Akos, R.; Knecht, M.; Salis, C.; Nebiker, M.; Theiler, R.; Pfeifer, M.; Begerow, B.; et al. Effects of vitamin D and calcium supplementation on falls: A randomized controlled trial. J. Bone Miner. Res. 2003, 18, 343-351.

51. Visser, M.; Deeg, D.J.; Lips, P. Low vitamin D and high parathyroid hormone levels as determinants of loss of muscle strength and muscle mass (sarcopenia): The Longitudinal Aging Study Amsterdam. J. Clin. Endocrinol. Metab. 2003, 88, 5766-5772.

52. Chapuy, M.C.; Arlot, M.E.; Delmas, P.D.; Meunier, P.J. Effect of calcium and cholecalciferol treatment for three years on hip fractures in elderly women. BMJ 1994, 308, 1081-1082.

53. Dawson-Hughes, B.; Harris, S.S.; Krall, E.A.; Dallal, G.E. Effect of calcium and vitamin D supplementation on bone density in men and women 65 years of age or older. N. Engl. J. Med. 1997, 337, 670-676. 
54. Flicker, L.; Mead, K.; MacInnis, R.J.; Nowson, C.; Scherer, S.; Stein, M.S.; Thomasx, J.; Hopper, J.L.; Wark, J.D. Serum vitamin D and falls in older women in residential care in Australia. J. Am. Geriatr. Soc. 2003, 51, 1533-1538.

55. Ring, S.M.; Dannecker, E.A.; Peterson, C.A. Vitamin D status is not associated with outcomes of experimentally-induced muscle weakness and pain in young, healthy volunteers. J. Nutr. Metab. 2010, 2010, 674240.

56. Peake, J.M.; Nosaka, K.; Muthalib, M.; Suzuki, K. Systemic inflammatory responses to maximal versus submaximal lengthening contractions of the elbow flexors. Exerc. Immunol. Rev. 2006, 12, $72-85$.

57. Louw, J.A.; Werbeck, A.; Louw, M.E.; Kotze, T.J.; Cooper, R.; Labadarios, D. Blood vitamin concentrations during the acute-phase response. Crit. Care Med. 1992, 20, 934-941.

58. Reid, D.; Toole, B.J.; Knox, S.; Talwar, D.; Harten, J.; O’Reilly, D.S.; Blackwell, S.; Kinsella, J.; McMillan, D.C.; Wallace, A.M. The relation between acute changes in the systemic inflammatory response and plasma 25-hydroxyvitamin D concentrations after elective knee arthroplasty. Am. J. Clin. Nutr. 2011, 93, 1006-1011.

59. Barker, T.; Martins, T.B.; Kjeldsberg, C.R.; Trawick, R.H.; Hill, H.R. Circulating interferon-gamma correlates with $1,25(\mathrm{OH}) \mathrm{D}$ and the $1,25(\mathrm{OH}) \mathrm{D}-\mathrm{to}-25(\mathrm{OH}) \mathrm{D}$ ratio. Cytokine 2012, 60, 23-26.

60. Koeffler, H.P.; Reichel, H.; Bishop, J.E.; Norman, A.W. Gamma-interferon stimulates production of 1,25-dihydroxyvitamin D3 by normal human macrophages. Biochem. Biophys. Res. Commun. 1985, 127, 596-603.

61. Reichel, H.; Koeffler, H.P.; Barbers, R.; Norman, A.W. Regulation of 1,25-dihydroxyvitamin D3 production by cultured alveolar macrophages from normal human donors and from patients with pulmonary sarcoidosis. J. Clin. Endocrinol. Metab. 1987, 65, 1201-1209.

62. Stoffels, K.; Overbergh, L.; Giulietti, A.; Verlinden, L.; Bouillon, R.; Mathieu, C. Immune regulation of 25-hydroxyvitamin-D3-1alpha-hydroxylase in human monocytes. J. Bone Miner. Res. 2006, 21, 37-47.

63. Stoffels, K.; Overbergh, L.; Bouillon, R.; Mathieu, C. Immune regulation of 1alpha-hydroxylase in murine peritoneal macrophages: unravelling the IFNgamma pathway. J. Steroid. Biochem. Mol. Biol. 2007, 103, 567-571.

64. Overbergh, L.; Stoffels, K.; Valckx, D.; Giulietti, A.; Bouillon, R.; Mathieu, C. Regulation of 25-hydroxyvitamin D-1alpha-hydroxylase by IFNgamma in human monocytic THP1 cells. J. Steroid. Biochem. Mol. Biol. 2004, 89-90, 453-455.

65. Edfeldt, K.; Liu, P.T.; Chun, R.; Fabri, M.; Schenk, M.; Wheelwright, M.; Keegan, C.; Krutzik, S.R.; Adams, J.S.; Hewison, M.; Modlin, R.L. T-cell cytokines differentially control human monocyte antimicrobial responses by regulating vitamin D metabolism. Proc. Natl. Acad. Sci. USA 2010, 107, 22593-22598.

66. Weinstock, C.; Konig, D.; Harnischmacher, R.; Keul, J.; Berg, A.; Northoff, H. Effect of exhaustive exercise stress on the cytokine response. Med. Sci. Sports Exerc. 1997, 29, 345-354.

67. Malm, C.; Sjodin, B.; Sjoberg, B.; Lenkei, R.; Renstrom, P.; Lundberg, I.E.; Ekblom, B. Leukocytes, cytokines, growth factors and hormones in human skeletal muscle and blood after uphill or downhill running. J. Physiol. 2004, 556, 983-1000. 
68. Barker, T.; Henriksen, V.T.; Martins, T.B.; Kjeldsberg, C.R.; Hill, H.R. Fluctuations in the skeletal muscle power-velocity relationship and interferon-gamma after a muscle-damaging event in humans. Extrem. Physiol. Med. 2012, 1, 1-6.

69. Peake, J.M.; Suzuki, K.; Hordern, M.; Wilson, G.; Nosaka, K.; Coombes, J.S. Plasma cytokine changes in relation to exercise intensity and muscle damage. Eur. J. Appl. Physiol. 2005, 95, 514-521.

70. Hirose, L.; Nosaka, K.; Newton, M.; Laveder, A.; Kano, M.; Peake, J.; Suzuki, K. Changes in inflammatory mediators following eccentric exercise of the elbow flexors. Exerc. Immunol. Rev. 2004, 10, 75-90.

71. Duncan, A.; Talwar, D.; McMillan, D.C.; Stefanowicz, F.; O’Reilly, D.S. Quantitative data on the magnitude of the systemic inflammatory response and its effect on micronutrient status based on plasma measurements. Am. J. Clin. Nutr. 2012, 95, 64-71.

72. Martins, T.B.; Pasi, B.M.; Pickering, J.W.; Jaskowski, T.D.; Litwin, C.M.; Hill, H.R. Determination of cytokine responses using a multiplexed fluorescent microsphere immunoassay. Am. J. Clin. Pathol. 2002, 118, 346-353.

73. Martins, T.B.; Anderson, J.L.; Muhlestein, J.B.; Horne, B.D.; Carlquist, J.F.; Roberts, W.L.; Carlquist, J.F. Risk factor analysis of plasma cytokines in patients with coronary artery disease by a multiplexed fluorescent immunoassay. Am. J. Clin. Pathol. 2006, 125, 906-913.

74. Barker, T.; Leonard, S.W.; Hansen, J.; Trawick, R.H.; Ingram, R.; Burdett, G.; Lebold, K.M.; Walker, J.A.; Traber, M.G. Vitamin E and C supplementation does not ameliorate muscle dysfunction following anterior cruciate ligament surgery. Free Radic. Biol. Med. 2009, 47, 1611-1618.

75. Webb, A.R.; Kline, L.; Holick, M.F. Influence of season and latitude on the cutaneous synthesis of vitamin D3: Exposure to winter sunlight in Boston and Edmonton will not promote vitamin D3 synthesis in human skin. J. Clin. Endocrinol. Metab. 1988, 67, 373-378.

76. Brancaccio, P.; Limongelli, F.M.; Maffulli, N. Monitoring of serum enzymes in sport. $B r . J$. Sports Med. 2006, 40, 96-97.

77. Nie, J.; Tong, T.K.; George, K.; Fu, F.H.; Lin, H.; Shi, Q. Resting and post-exercise serum biomarkers of cardiac and skeletal muscle damage in adolescent runners. Scand. J. Med. Sci. Sports 2011, 21, 625-629.

78. Dusso, A.S.; Kamimura, S.; Gallieni, M.; Zhong, M.; Negrea, L.; Shapiro, S.; Slatopolsky, E. Gamma-interferon-induced resistance to 1,25-(OH)2 D3 in human monocytes and macrophages: A mechanism for the hypercalcemia of various granulomatoses. J. Clin. Endocrinol. Metab. 1997, $82,2222-2232$.

79. Adams, J.S.; Gacad, M.A. Characterization of 1 alpha-hydroxylation of vitamin D3 sterols by cultured alveolar macrophages from patients with sarcoidosis. J. Exp. Med. 1985, 161, 755-765.

80. Reiss, A.B.; Awadallah, N.W.; Malhotra, S.; Montesinos, M.C.; Chan, E.S.; Javitt, N.B.; Cronstein, B.N. Immune complexes and IFN-gamma decrease cholesterol 27-hydroxylase in human arterial endothelium and macrophages. J. Lipid Res. 2001, 42, 1913-1922. 
81. Overbergh, L.; Decallonne, B.; Valckx, D.; Verstuyf, A.; Depovere, J.; Laureys, J.; Rutgeerts, O.; Saint-Arnaud, R.; Bouillon, R.; Mathieu, C. Identification and immune regulation of 25-hydroxyvitamin D-1-alpha-hydroxylase in murine macrophages. Clin. Exp. Immunol. 2000, 120, 139-146.

82. Monkawa, T.; Yoshida, T.; Hayashi, M.; Saruta, T. Identification of 25-hydroxyvitamin D3 1alpha-hydroxylase gene expression in macrophages. Kidney Int. 2000, 58, 559-568.

83. Quinlan, G.J.; Martin, G.S.; Evans, T.W. Albumin: Biochemical properties and therapeutic potential. Hepatology 2005, 41, 1211-1219.

84. Green, H.J.; Thomson, J.A.; Ball, M.E.; Hughson, R.L.; Houston, M.E.; Sharratt, M.T. Alterations in blood volume following short-term supramaximal exercise. J. Appl. Physiol. 1984, 56, 145-149.

85. Gillen, C.M.; Lee, R.; Mack, G.W.; Tomaselli, C.M.; Nishiyasu, T.; Nadel, E.R. Plasma volume expansion in humans after a single intense exercise protocol. J. Appl. Physiol. 1991, 71, 1914-1920.

86. Yang, R.C.; Mack, G.W.; Wolfe, R.R.; Nadel, E.R. Albumin synthesis after intense intermittent exercise in human subjects. J. Appl. Physiol. 1998, 84, 584-592.

87. Bikle, D.D.; Gee, E.; Halloran, B.; Kowalski, M.A.; Ryzen, E.; Haddad, J.G. Assessment of the free fraction of 25-hydroxyvitamin $\mathrm{D}$ in serum and its regulation by albumin and the vitamin D-binding protein. J. Clin. Endocrinol. Metab. 1986, 63, 954-959.

88. Garabedian, M.; Holick, M.F.; DeLuca, H.F.; Boyle, I.T. Control of 25-hydroxycholecalciferol metabolism by parathyroid glands. Proc. Natl. Acad. Sci. USA 1972, 69, 1673-1676.

89. Rasmussen, H.; Wong, M.; Bikle, D.; Goodman, D.B. Hormonal control of the renal conversion of 25-hydroxycholecalciferol to 1,25-dihydroxycholecalciferol. J. Clin. Invest. 1972, 51, 2502-2504.

90. Fraser, D.R.; Kodicek, E. Regulation of 25-hydroxycholecalciferol-1-hydroxylase activity in kidney by parathyroid hormone. Nat. New Biol. 1973, 241, 163-166.

91. Boyle, I.T.; Gray, R.W.; DeLuca, H.F. Regulation by calcium of in vivo synthesis of 1,25-dihydroxycholecalciferol and 21,25-dihydroxycholecalciferol. Proc. Natl. Acad. Sci. USA 1971, 68, 2131-2134.

(C) 2013 by the authors; licensee MDPI, Basel, Switzerland. This article is an open access article distributed under the terms and conditions of the Creative Commons Attribution license (http://creativecommons.org/licenses/by/3.0/). 